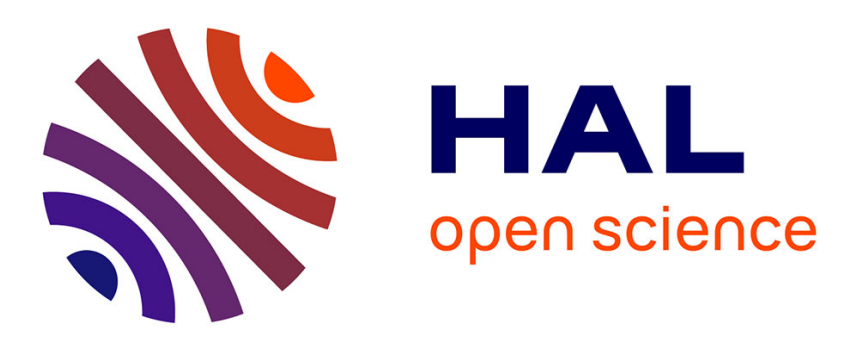

\title{
InBookModE: An Interactive Book and Model Environment to Link BIM and AEC Education
}

Vishal Singh

\section{To cite this version:}

Vishal Singh. InBookModE: An Interactive Book and Model Environment to Link BIM and AEC Education. 15th IFIP International Conference on Product Lifecycle Management (PLM), Jul 2018, Turin, Italy. pp.93-103, 10.1007/978-3-030-01614-2_9 . hal-02075575

\section{HAL Id: hal-02075575 \\ https://hal.inria.fr/hal-02075575}

Submitted on 21 Mar 2019

HAL is a multi-disciplinary open access archive for the deposit and dissemination of scientific research documents, whether they are published or not. The documents may come from teaching and research institutions in France or abroad, or from public or private research centers.
L'archive ouverte pluridisciplinaire HAL, est destinée au dépôt et à la diffusion de documents scientifiques de niveau recherche, publiés ou non, émanant des établissements d'enseignement et de recherche français ou étrangers, des laboratoires publics ou privés.

\section{(c)(1)}

Distributed under a Creative Commons Attribution| 4.0 International License 


\title{
InBookModE: An interactive book and model environment to link BIM and AEC education
}

\author{
Author surname, First Initials \\ Address \\ Corresponding author: email
}

\begin{abstract}
Building Information Modeling (BIM) tools have become a knowledge resource in the Architecture Engineering and Construction (AEC) sector. While effective BIM use requires knowledge and skills with the tools, BIM tools can also become a good source of learning about the core domain area e.g. architecture, engineering, etc. However, effective teaching and learning of BIM and core domain knowledge is challenging, especially when BIM tools are becoming specialized and complex. So how do we train and skill people both in the use and potential of technology, as well as in their core domain knowledge? To address this challenge, we propose a learning platform, InBookModE (Interactive Book and Model Environment), that integrates acquisition of BIM knowledge with domain knowledge. The main objectives of the proposed approach are to (1) Implement and test the efficacy of an interactive learning platform that integrates the BIM tools with the information encoded in textbooks (2) Combine the interactivity and usability of ebooks with BIM applications to enhance wider adoption and learning, and (3) Create the basis for a long-term goal of a digital repository of interactive BIM case studies. This paper introduces the key ideas and concepts behind the InBookModE, with a brief discussion on the current status of the project and the findings so far.
\end{abstract}

\section{$1 \quad$ Introduction}

Building Information Modeling (BIM) provides digital tools and approaches to effectively create and manage built facilities across the lifecycle (Eastman et al 2008), which can have potentially huge economic, environmental and societal impact. This belief in the potential capabilities and impacts of BIM has resulted in global attention towards BIM across the Architecture Engineering and Construction (AEC) industry, academia and the policy makers (Bew and Underwood 2010). For example, a McGraw-Hill Research (Bernstein et al. 2012) reports that within five years, between 2007 and 2012, BIM adoption in the US grew from $17 \%$ to $70 \%$. Given this growing interest in BIM and its potential wide-ranging scope, the number of BIM-based products and services have increased manifold. As a result, more and more expert knowledge is being encoded into the BIM software for targeted purposes such as performance analysis, code checking, etc, which are making the BIM tools increasingly complex. The increasing emphasis on BIM in AEC, combined with the increasing complexity of BIM tools, is creating the following unintended effects and challenges that need to be addressed:

adfa, p. 1, 2011.

(C) Springer-Verlag Berlin Heidelberg 2011 
1. There is an extreme shortage of multi-skilled AEC professionals with a combination of domain expertise (core disciplinary and traditional knowledge) and BIM and ICT expertise (to augment their competence)

2. The increasing complexity of BIM tools means there is greater cognitive and learning load on individuals to simultaneously gain domain expertise as well as the expertise in using BIM technologies efficiently

3. There is an increasing need and pressure in the tertiary institutes to rethink AEC curriculum and pedagogy to balance and seamlessly integrate BIM and technology education with core disciplinary education

Besides these challenges, there are new opportunities for improvements in AEC education and learning through cross-disciplinary knowledge transfer from other fields. The emergence of learning technologies, and self-learning and distributed learning platforms such as MOOCS (massive open online courses) have created further opportunity and need to rethink teaching and learning (Eckerdal et al 2014).

Therefore, this paper presents the details and preliminary results from an ongoing research project aimed at addressing these gaps and opportunities at the interface of BIM and AEC education. The key research questions are: (Q1) How can BIM education be seamlessly integrated with the education and learning about AEC? (Q2) How can the contents and tools required for BIM education be integrated with the traditional contents and tools used in AEC education, for example, textbooks? And, (Q3) How can we leverage the advancements in learning technologies to address the problems stated in Q1 and Q2? (Q4) What will be the intended and unintended cognitive effects and impacts of InBookModE for learning, skills development and technology integration in AEC? And, (Q5) What new educational methods and techniques will emerge as a result of the InBookModE? These fundamental research enquiries will lead to new knowledge and theories in the context of BIM and AEC education.

\section{Background}

The potential impact of BIM on the AEC sector is globally recognized, which has fueled rapid growth and interest across the industry, academia and the policy makers. For example, government agencies across countries such as Australia, US and the UK have recently taken steps towards national BIM guidelines, regulations and policy interventions to facilitate BIM integration and adoption across the AEC sector (e.g. Fussel et al. 2009, AIA 2007, Bew and Underwood 2010). The UK government has even mandated that all public sector, centrally procured, construction projects will be delivered using BIM by 2016. Similarly, the Finnish government's real estate organization, termed Organization-S here, has already mandated the submission of BIM model for all its new projects since 2007. Despite such mandates, there is growing concern on the alarming shortage of multi-skilled AEC professionals with a combination of domain expertise and BIM expertise (CIOB 2013). This shortage of BIM skilled AEC professionals is significant because it poses serious threats to achieving the targeted levels of BIM adoption and usage, which in turn can jeopardize the desired levels of productivity and performance improvements in AEC sector that can be achieved using BIM tools 
and approaches. For example, in the case of Organization-S, despite the mandated use of BIM since 2007, the organization has failed to use BIM to the intended effect due to shortage of AEC professionals that could deliver quality BIM models, as well as those who could use and integrate the delivered models in their activities (Holmström et al 2014). Consequently, BIM education and training, skills development and integration are seen as critical bottlenecks that need immediate attention for the advancement and productivity improvements in the AEC sector. In the AEC literature and academic research, BIM education and training is beginning to emerge as a significant research topic (Sacks and Barak 2010). Yalcinkaya and Singh's (2015) analysis shows "BIM education and curriculum development" as one of the most popular theme within BIM research with significant jump between 2012-2014. Academic research so far has been focused on BIM curriculum development, multi-disciplinary classroom environments, and project-based learning, but considerably little has been reported towards the development of BIM-related learning technologies.

On the other hand, the research and development in learning technologies in recent years has shown significant advancements in the areas of rich interactive learning tools, and self-learning and distributed learning platforms such as MOOCS (Brusilovsky et al 2014, Korhonen et al 2013). These developments provide opportunities for cross-disciplinary knowledge transfer. This has opened up new opportunities for transforming $\mathrm{BIM}$ and AEC education, and there are potentially significant theoretical and practical contributions that are yet to be made.

\subsection{Notable trends in learning and teaching}

The learning and teaching approaches, especially at the level of tertiary education is seeing significant changes brought about by technology mediation, increasing awareness and recognition of modern pedagogical methods and approaches in engineering education, and changes in educational policies and expectations. Some of the notable trends relevant to this study include:

- Emphasis on blended learning, which combines online digital media with traditional classroom methods. There is expectation that while the face to face sessions and contact teaching continue with the physical presence of both the teacher and the students, there would be complementary elements of the courses that allow some of the control in the hands of the students, including when they learn, where they learn, in what order do they learn the content, and at what pace? Thus, there is a clear trend to combine face-to-face classroom practices with computermediated activities regarding content and delivery. In BIM-related courses where students also need hands-on computer-based sessions such a combination is natural. However, the combination and integration between lecture sessions in AEC courses and BIM exercises and assignments are still not seamlessly streamlined, and there is opportunity for better blended learning experience.

- Online and open learning: With the explosion of online learning material and learning sources, and with increasing acceptance of distance learning and open learning approaches, there is greater demand and expectation on quality online and 
open learning opportunities. Regular students as well as open learning students might be enrolled in the same courses, and hence, several courses are expected to have well developed delivery methods to support online learning.

- Flipped-classroom: Together with blended learning and online learning, flipped classroom is intended to facilitate learner driven teaching practice. Students explore the topics and learning material of their interest, and the student picked contents become the focus of classroom discussions. Consequently, one of the roles of the teachers and instructors is to curate quality content for the students to explore and choose from for classroom discussions. This creates opportunity as well as the need to have online databases and libraries of interactive content, which can foster content search, filtering, self-driven exploration, and follow-up activities.

- Case-based and Project-based learning: In various traditional disciplines, best practices have evolved over years of experience. For example, design-based courses such as in architecture, software design, and engineering design are mostly planned around project-based learning, whereas courses in management departments are often planned around case-reviews and case-based learning. Consequently, with the growing emergence of multi-disciplinary courses case-based and project-based learning are becoming increasingly central to teaching and education. Since BIM and Product Lifecycle Management (PLM) courses are multidisciplinary at the interface of engineering, design and management, case-based and project-based learning is in particularly relevant to these courses.

- Virtual learning environments (VLEs) in engineering education: VLEs have been proven to be more engaging and attractive to students. With increasing maturity of Virtual Reality (VR) and Augmented Reality (AR) kits, the role and scope of VLEs is expected to grow exponentially in coming years. So far one of the biggest drawbacks of VLEs have been its development cost and skills. On the other hand, VR and AR applications based on BIM could provide students clear view of the learning content, more complete and detailed visual information, and also an ability to study all the architectural details, structures, constructions and joints within the augmented environment. With greater availability of BIM and PLM models and libraries, the basis for VLE content development is available.

\subsection{Challenges in planning and delivering BIM courses}

The expectation and need from BIM educators and teachers to be able to respond to the emerging trends, together with the breadth of topics to cover in typical BIM courses, poses several challenges for academics offering such courses. Several factors need to be considered in developing BIM courses and the learning material, such as

- Connecting the dots between the different AEC theories and topics and methods and the practical tools that need to be introduced in the courses. Collectively, the amount and breadth of content to cover has increased. Besides the traditional and fundamental engineering content that needs to be covered, additional content related to tools and their applications needs to be covered. 
- Managing workload for students: Not only do the instructors and teachers need to consider their own workload, there is growing recognition that students' workload in courses should allow them time and space to reflect on their learning. This means better selection of material and content which facilitates comprehension, and allows learning in more comfortable and informal settings.

- Developing and updating content which is rapidly changing: Several aspects of relatively new topics such as BIM and PLM tend to change frequently. New tools, applications, and research-based findings need to be introduced into the courses as they emerge, and hence, the teaching material and content should be easy to update.

- Increasingly provide more content via interactive and digital media: Digital natives differ in how they learn and how they consume data. With various aspects of everyday life shifting to digital media, interactive learning is becoming a norm, and teaching material and delivery needs to take advantage of this change.

- Facilitating social processes and interaction: As is emphasized in modern pedagogical approaches, situated learning and interaction among learners is desirable. Several authors have noted that social interactions facilitate and reinforce learning (e.g. Singh et al, 2013). In particular, for courses such as BIM and PLM, several soft skills are desirable which can only be developed in how the content and course is delivered, rather than the content itself. Thus, online and digital learning environments also need to support such interaction, especially when it may limit some of the modes of interaction that are available in collocated settings. Furthermore, tertiary education increasingly involves diverse set of students, including those attending courses from remote locations. Thus, it is important to ensure mechanisms that allow these diverse set of students to interact as well.

\subsection{Unique opportunities for BIM and PLM based learning platforms}

BIM and PLM tools and applications offer unique features and characteristics that are particularly conducive to integrate them in learning platforms. For example,

- BIM and PLM tools can be viewed as knowledge resources (Jupp and Singh, 2014) where a lot of domain knowledge is encoded in form of object libraries and attributes, standards and regulations, relationships and constraints between objects, performance analysis and code- checking rules, etc. BIM tools and applications are increasingly viewed as collaboration tools allowing exchange of ideas, representations and comments, and at the same time facilitating documentation of the generated knowledge (Singh et al, 2011). The concepts and models created by one set of designers may also be available to the next set of designers and team members in form of custom libraries and templates within organizations and project teams $(\mathrm{Gu}$ et al, 2014). With a range of BIM applications and tools available to support ' $\mathrm{nD}$ ' simulations and modeling, BIM can also be viewed as a decision support system, providing knowledge support to the project team members. All this documentation, makes BIM models and platforms particularly useful as learning resources.

As shown in Figure 1, there are different ways and levels of detail in using BIM as a source of learning. At the basic level access to details of BIM objects and object 
attributes can allow learning about building and construction objects, materials, etc. For example, a window BIM object can be used to explain how a window is detailed, what kind of material is used, what are the attributes to consider, etc. Similarly, case projects and buildings are often used to explain design and engineering principles. Such case projects allow limited context and content, but focused learning objectives. For instance, the design of a specific building (e.g. FallingWater) could be used to explain its designer's (e.g Frank Lyod Wright) design philosophy or a design principle specifically applied or demonstrable in the chosen case. Thus, a single BIM model of a specific case can be used for targeted learning objectives. In contrast, access to all the resources available in a BIM software could allow much wider content and learning possibility. For instance, a structure engineering BIM software would typically have a large repository of structural elements and components that follow one or more standard, rules and constraints defining relationships between different objects and object attributes, etc.

However, all the information and knowledge encoded in the BIM objects, or models, or software are not particularly structured in a way that is directly conducive to learning. Typically, descriptive text is required to explain the content. Thus, BIM related content needs to be integrated with textbooks or reports explaining that content. While BIM objects and models can be integrated in a separate learning platform, access to all the content within BIM software would require interoperable interfaces with the BIM software or embedding the learning platform within a BIM software. Since there are numerous BIM software, each with their own proprietary solutions, implementing a learning system that can be embedded within different BIM software applications is challenging. Therefore, the InBookModE research currently focusses on developing a learning platform that can use BIM objects and BIM models as learning resources. Future work would aim at developing widgets and plug-ins allowing the InBookModE platform to be used within BIM software.

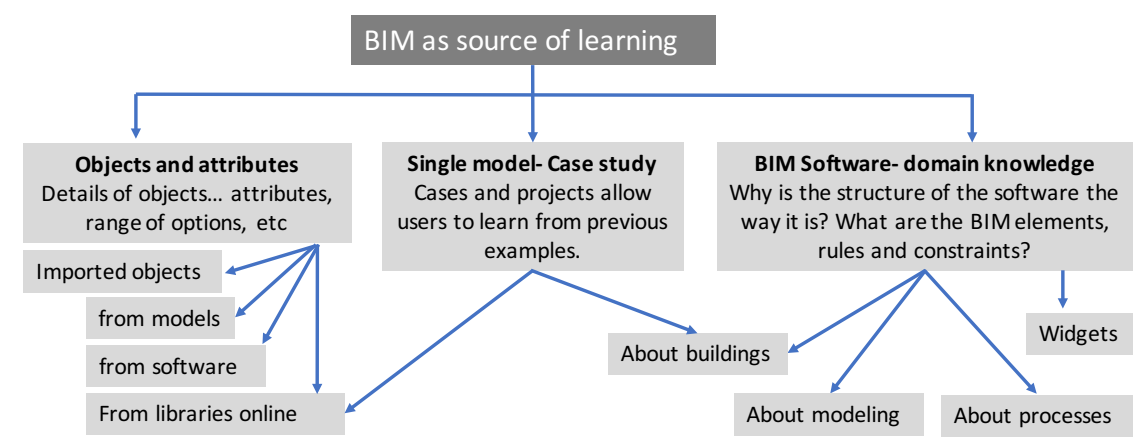

Figure 1: Opportunities with BIM as a source of learning

- There is a trend towards both vertical and horizontal integration of BIM education in AEC curricula (Suwal and Singh, 2016). Vertical integration refers to the level of education such as undergraduate or postgraduate level. Horizontal integration 
refers to multidisciplinarity and breadth of education such as architecture, engineering, mechanical-electrical-plumbing (MEP) education, etc.

- Suwal and Singh (2016) found that online BIM learning platforms are highly rated by students as a positive learning experience. They also found that the integration of easy-to-use online BIM learning platforms where students can learn at their own pace, and practice their skills, results in improved engagement and learning.

\section{Development and implementation}

The InBookModE development and implementation is currently underway. A working prototype has been developed with basic functionalities, but full-scale user testing to validate and test the research questions and hypotheses is still to be done. Preliminary details and some findings from the implementation so far are presented here.

\subsection{What has been implemented so far?}

A working prototype of InBookModE with separate authoring and reader interface and login has been implemented. The system is based on integration between open BIMServer to access open standard BIM data, Unity engine for interactive game interface, and web-technologies. Figure 2 shows the system architecture. Figures 3 and 4 show snapshots from the current implementation, each supported with a brief description.

The 'user' in Figure 3 refers to students, who can login (Figure 4a) into the InBookModE library, access the books and the interactive 3D models associated with the books. A bookstore has been implemented where all books chosen by the students are maintained in their bookshelf (Figure $4 b$ ).

The 'admin' refers to the teachers and content providers who have access to the back end. These actors have the ability to create book content, including uploading and connecting BIM models relevant to the book contents, link the model data with the book data. The admin users can also maintain user accounts, and check usage patterns.

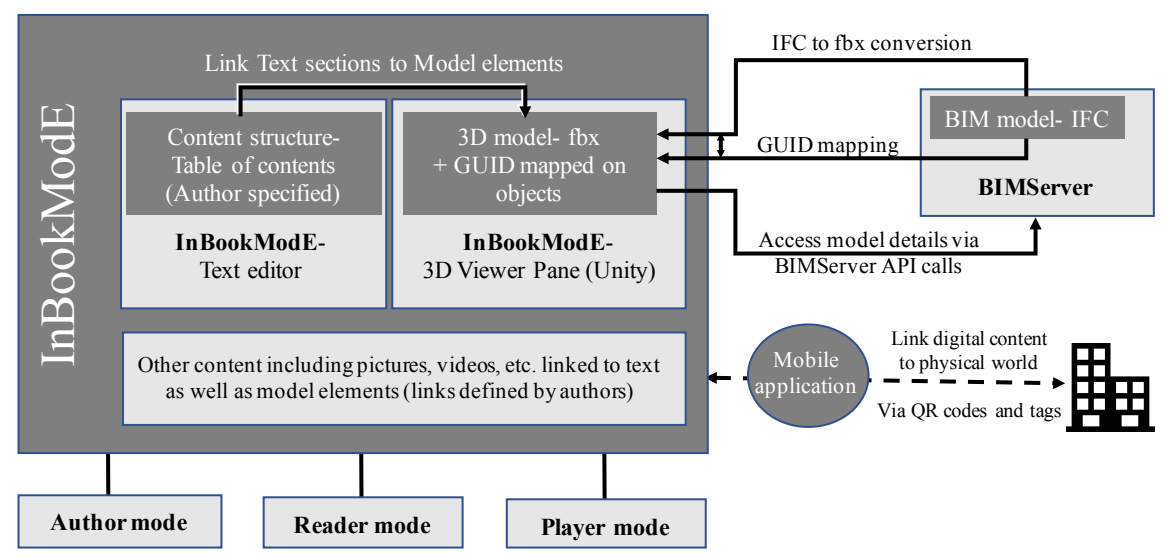

Fig.2: System architecture for InBookModE 


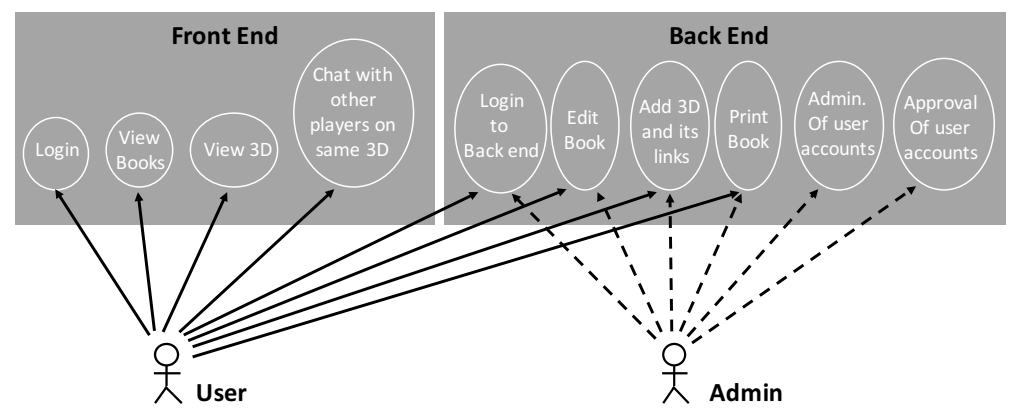

Fig.3: Use case diagram

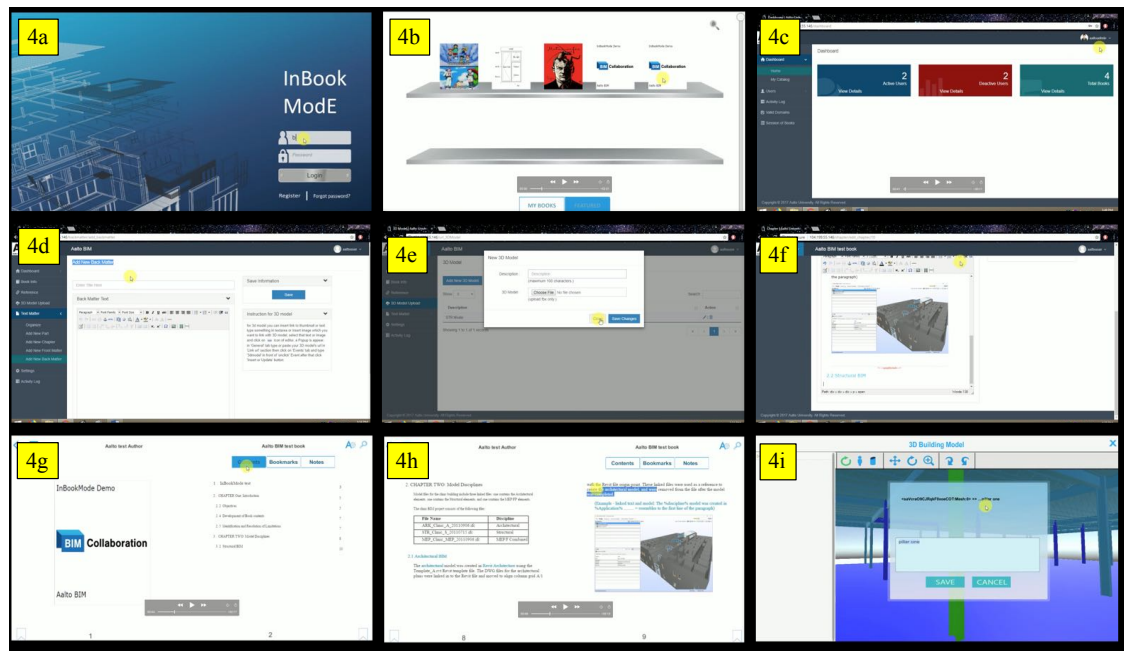

Fig. 4. Snapshots from the implementation of InBookModE prototype

The admin or the teacher can see details such as who are the active and non-active users, what are activity logs, how long do users spend on which book, what is the total number of books, etc. (Figure 4c). The admin account allows login into the authoring mode, whereby the teachers can create new content (Figures 4d-4f). The interface allows content developers to organize their book and preview as it progresses. Help tips such as how to add 3D content etc. are also provided.

InBookModE has a book interface (Figure 4g) with standard book elements such as table of contents, bookmarks, ability of tagging and taking notes, etc. InBookModE platform also allows embedding and linking processed BIM models into the book interface (Figure 4h). The BIM model is processed to make it lighter, while the GUIDs of the model elements are retained. Using these GUIDs it is possible to fetch relevant data from BIMServer, while allowing interactive navigation of the model. The authors can also link the model elements with parts of the book text. The model elements can be linked directly to book sections, or paragraphs, or sentences and words, etc. The 3D model can be navigated within the frame or can be viewed on a pop-up window. 
To enhance interactive experience, including social and situated learning, a multiuser learning session has been implemented (4i). More than one user, including students and teachers can interact with the same content, and interact with chats. The typed text can be tagged to different model elements and saved for later reference and use. The left side of the interface allows showing model tree structure based on IFC or other classification of the model data.

\subsection{Testing and validation}

While a full-fledged testing with students has not been achieved yet, the research team was able to test the usability and functionality of the initial working prototype, especially during development of sample content. This was done to explore different implementation features and how usable these functionalities were. The images above are based on such sample testing. Currently, two case projects are being detailed with respect to BIM models as well as reports relating to those models. Some of the insights from the implementation and sample content development so far include:

- Even though the number of available BIM models is increasing rapidly, in most BIM models the meta-data is either not well documented, or is not directly suitable for direct training and education. Nonetheless, even without adequate and relevant meta-data the models can be useful for interaction and visualization.

- Following on the previous point, it is important to prune BIM models to be linked into the InBookModE such that only the relevant and filtered data is accessed. Otherwise it leads to performance issues as large models can slow down the interactions. In some cases, it is perhaps desirable to develop well-documented BIM models specifically for the purpose of education and training.

- Mapping and structuring the book content with the used BIM content offers various possibilities, which vary with the types of books and specific cases to be written. This means, it is desirable to develop default templates to support authors and reduce the complexity of the mapping and linking activities.

\section{Conclusion}

This paper reports the development of a BIM-based learning platform, InBookModE, which allows interactive links between digital books and associated BIM models. Thus, it is possible for students to bi-directionally navigate between models and textbooks, or even between related models, textbooks and other linked or embedded sources from the InBookModE interface. Preliminary functionalities and sample content has been developed to test the technical feasibility and integration of the different requirements. A full-scale testing with students to validate whether the learning platform enhances and augments learning experience and comprehension is part of the future work. 


\section{References}

1. AIA. 2007. Integrated Project Delivery: A Guide. http://www.aia.org/contractdocs/AIAS077630

2. Bernstein, HM (Ed) 2012. The Business Value of BIM in North America: Multi-year Trend Analysis and User Ratings (2007-2012), SmartMarket Report, McGraw-Hill Res. Findings.

3. Bew, M., \& Underwood, J. 2010. Delivering BIM to the UK Market. In J. Underwood, \& U. Isikdag (Eds.), H'book of Res. on BIM and Const. Info.: Concepts \& Tech. (pp. 30-64).

4. Brusilovsky, P, Edwards, S, Kumar, A, Malmi, L (co-chairs), et al. 2014. Increasing Adoption of Smart Learning Content for Computer Science Education, ITiCSE Working group report, submitted for publication, 2014.

5. CIOB. 2013. A report exploring skills in the UK Construction Industry, The Chartered Institute of Building, April'13.

6. Eastman, C, Teicholz, P, Sacks, R and Liston, K. 2008. BIM Handbook: A Guide to BIM for Owners, Managers, Designers, Engineers \& Contractors, John Wiley \& Sons, NY.

7. Eckerdal, A, Kinnunen, P, Thota, N, Nylén, A, Sheard, J and Malmi, L. 2014. Teaching and learning with MOOCs: computing academics' perspectives and engagement. In Proc. of the Conf. on Innov. \& Tech. in Computer Sc. Education (ITiCSE '14). ACM, NY, USA, 9-14.

8. Fussel, T., Beazley, S., et al. 2009. National guidelines for digital modelling. Brisbane, QLD.

9. Gu, N, Singh, V and London, K. 2014. BIM Ecosystem: The Coevolution of Products, Processes, and People, (in) Building Information Modeling: BIM in Current and Future Practice. Ed. Kensek, K and Noble, D, pp.197-211

10. Holmström, J, Singh, V and Främling. K. 2014. BIM as Infrastructure in a Finnish HVAC Actor Network: Enabling Adoption, Reuse, and Recombination over a Building Life Cycle and between Projects. J. Mana. Eng., 10.1061/(ASCE)ME.1943-5479.0000305, A4014006.

11. Jupp, J and Singh, V. 2014. Similar Concepts, Distinct Solutions, Common Problems: Learning from PLM and BIM Deployment, In'l Conf. on Prod. Lif. Man., Yokohama, Japan.

12. Korhonen, A, Naps, T, Boisvert, C, et al. 2013. Requirements and Design Strategies for Open Source Interactive Computer Science eBooks. ITiCSE Working Gr'p Reports Conf. on Innov. \& Tech. in Comp. Sc. Edu. -WGR '13, pgs 53 \{72, NY, USA, 2013. ACM.

13. Sacks, R. and Barak, R. (2010). Teaching Building Information Modeling as an Integral Part of Freshman Year Civil Engineering Education. J. Prof. Iss. Eng. Edu. Prac., 136(1), 30-38.

14. Singh, V, Dong, A and Gero, JS. 2013. Social learning in design teams: The importance of direct and indirect communications. Art. Int. for Eng. Des., Anal. and Manuf., 27, 167-182.

15. Singh, V., Gu, N., Taylor, C., London, K., Brankovich, L. 2009. Collaboration Platform: Final Report. CRC Constr. Inno, Australia. http://eprints.qut.edu.au/27997/1/27997.pdf

16. Singh, V 2014. BIM and systemic ICT innovation in AEC: perceived needs and actor's degrees of freedom, Construction Innovation: Information, Process, Management, 14(3)

17. Singh, V, Gu, N and Wang, X. 2011. A theoretical framework for BIM-based multi-disciplinary collaboration platform, Automation in Construction 20, 134-144.

18. Suwal, S and Singh, V. 2016. Assessing students' sentiments towards the use of a Building Information Modelling (BIM) learning platform in a construction project management course, European Journal of Engineering Education, 10.1080/03043797.2017.1287667

19. Yalcinkaya, M. and Singh, V., 2015. Patterns and trends in Building Information Modeling (BIM) research: A Latent Semantic Analysis. Automation in Construction, 59, pp.68-80 